\title{
When size matters: The gonads of larger female yellowfin tuna (Thunnus albacares) have different fatty acid profiles compared to smaller individuals
}

\author{
Pecoraro C. 1, ${ }^{*}$, Zudaire I. ${ }^{2}$, Galimberti G. ${ }^{3}$, Romeo M. ${ }^{4}$, Murua H. ${ }^{5}$, Fruciano C. ${ }^{6}$, Scherer C. ${ }^{7}$, \\ Tinti F. ${ }^{8}$, Diaha N.C. ${ }^{9}$, Bodin Nathalie ${ }^{10,11}$, Chassot Emmanuel ${ }^{10,11}$
}

\author{
1 Physalia-courses, Berlin, Germany \\ ${ }^{2}$ Azti tecnalia, Herrera Kaia, Portualdea z/g, Pasaia Gipuzkoa 20110, Spain \\ 3 Università di Bologna, Dipartimento di Scienze Statistiche "Paolo Fortunati", Via Belle Arti 41, Bologna, \\ Italy \\ 4 Oman Aquarium, Muscat, Oman \\ 5 International Seafood Sustainability Foundation (ISSF), 1440 G Street NW, Washington, DC 20005, \\ United States \\ ${ }^{6}$ Institut de Biologie de l'Ecole Normale Supérieure (IBENS), Ecole Normale Supérieure, CNRS, PSL \\ Université Paris, 75005 Paris, France \\ ${ }^{7}$ Leibniz Instiute for Zoo and Wildlife Research (IZW), Alfred-Kowalke-Str. 17, DE-10315 Berlin, \\ Germany \\ ${ }^{8}$ Laboratory of Genetics \& Genomics of Marine Resources and Environment, Dept. of Biological, \\ Geological \& Environmental Sciences, University of Bologna, 48100, Ravenna, Italy \\ ${ }^{9}$ Centre de Recherches Océanologiques, 29 Rue des Pêcheurs, B.P. V 18 Abidjan, Cote d'Ivoire \\ 10 Seychelles Fishing Authority, PO BOX 449, Victoria, Mahe, Seychelles \\ ${ }^{11}$ MARBEC, Univ. Montpellier, CNRS, Ifremer, IRD, Sète, France \\ * Corresponding author : C. Pecoraro, email address : info@physalia-courses.org
}

\begin{abstract}
:
How the size of female yellowfin tuna (Thunnus albacares) affects their spawning capability and fecundity is still an open and unresolved question due to the difficulties in investigating these complex effects in highly migratory pelagic marine fish species. However, this information is key to understanding the reproductive potential and resilience of the stock. We investigate how energetic resources are allocated for reproduction by female yellowfin tuna according to their size in the Gulf of Guinea (central-eastern Atlantic Ocean). Our results reveal that larger females have not only larger ovaries by virtue of their greater abdominal cavity, but also different fatty acid profiles in the gonads compared to smaller females, with potential effects on their spawning and recruitment patterns. This study contributes to the knowledge of size-dependent variation in female yellowfin tuna and paves the way for future studies on size-dependent effects on reproductive parameters in this species.
\end{abstract}

Keywords : Tuna fishery, Maternal effect, Yellowfin tuna, Reproductive potential 
43 Understanding the productivity and resilience of fish stocks, which contribute to define the level of

44 fishing mortality they can sustain and their ability to recover from depletion, is crucial to provide sound

45 scientific advice for fishery management (Morgan et al., 2009). However, the estimation of stock

46 productivity, which mainly relies on the stock-recruit relationship, is a difficult challenge in the study

47 of marine fish stocks' dynamics and management (Myers et al., 1998). The stock-recruitment

48 relationship is traditionally measured by estimating the spawning stock biomass and is used as a proxy

49 of stock reproductive potential (Trippel, 1999; Tomkiewicz et al., 2003; Lowerre-Barbieri et al., 2011).

50 Using spawning stock biomass for stock reproductive potential implies that the survival rates of

51 offspring are independent from parental age, body size and condition (Cardinale and Arrhenius, 2000),

52 and that the total egg production per unit weight is invariant over time (Morgan et al., 2009). Thus,

53 spawning stock biomass does not take into account a variety of fundamental attributes, such as the

54 fecundity, atresia, duration of reproductive season, daily spawning behaviour and spawning fraction

55 (Murua et al., 2003a).

56 Accurate knowledge of the reproductive characteristics that have a direct influence on the 57 productivity and resilience of commercial fish species is fundamental for developing effective and 58 realistic fishery management and conservation strategies (Trippel, 1999; Morgan et al., 2009; Brown-

59 Peterson et al., 2011). In this context, some concerns have been raised about the appropriateness of 60 spawning stock biomass (Marshall et al., 1998; 1999) as a proxy of reproductive potential, which 61 assumes that fecundity is related to the weight-at-age of the sexually mature portion of the stock 62 irrespective of the demographic composition of adults (Murawski et al., 2001; Kell et al., 2015). This, 63 for instance, equates to claiming that many smaller mature individuals with the same weight of few 64 large mature individuals will produce the same amount of offspring. This means that first time 65 spawners will produce the same (and of the same quality) amount of eggs per weight than repeat 66 spawners. On the contrary, there is an increasing consensus in fishery science that spawning stocks 67 are composed by individuals with a range of sizes and ages that may contribute differently to spawning 68 and recruitment (Marshall et al., 1998; Scott et al., 1999, Kell et al., 2015).

69 There is a general acknowledgment of the relevant impacts that "maternal effects" can have on 70 fecundity and viability of eggs and larvae (Kjesbu et al., 1998; Scott et al., 1999; Trippel, 1999; Berkeley 
et al., 2004). These effects include that larger females can allocate larger relative amounts of reproductive resources for postnatal use. The positive relationship between the mothers' size/age and both the potential productivity and the survival rates of the recruits has been demonstrated in other fish species (Marshall et al., 1998; 1999; Cardinale and Arrhenius, 2000; Shelton et al., 2015; Berkeley et al., 2004; Bobko and Berkeley, 2004; Riveiro et al., 2004). Moreover, older and larger females, having a wider spatial and temporal window for spawning than smaller females, concomitant with more spawning events in a season can enhance the perspectives for their larvae to encounter advantageous conditions to survive (Birkeland and Dayton, 2005). In doing so, larger females should invest a higher amount of energy for reproduction than smaller ones. This energy is mainly provided by the metabolization of lipids and their constituent fatty acids, which represent the main energetic resource in fish (Tocher, 2003).

Lipids can be divided into two main groups according to their chemical properties and functions: polar lipids (PLs) and neutral lipids (NLS). PLs mainly correspond to the lipid class of phospholipids and to a lesser extent to the ketones and wax-esters. PLs are important constituents of membranes and have an important role as precursors in eicosanoid metabolism, i.e. structural fat. Contrary, NLs comprising triacylglycerols and sterols - serve primarily as depot fat, mainly used as an energy source. Yet, the importance of fatty acids, specifically the omega- $6(\omega 6)$ arachidonic acid (AA: 20:4n-6) and those of the omega-3 ( $\omega 3$ ) type such as eicosapentaenoic acid (EPA: 20:5n-3) and docosahexaenoic acid (DHA: 22:6n-3), in fish reproduction is well known (Watanabe, 1982). Particularly important are also the polyunsaturated fatty acids (PUFAs), which are functionally essential for fish reproduction, influencing egg quality, spawning, hatching and larval survival (Sargent et al., 1989; 2002). PUFAs also intervene in regulating the production of eicosanoids, steroid hormones and gonad development (Izquierdo et al., 2001). Hence, fatty acid composition in both NLs and PLs can provide major insight for understanding fish energetic investment for reproduction.

The acquisition of lipids and their fatty acids relative to reproduction time follows two main strategies in fish: 1) capital breeders, which store the required energy before the onset of reproductive period, and 2) income breeders, which acquire it by feeding during the reproductive period (Murua et al., 2003b; Alonso-Fernández and Sabórido-Rey, 2012; Aristizabal, 2007). In income breeders, the fatty acid composition of the female gonad is greatly affected by dietary fatty acid content, which, in turn, directly influences the egg quality in a short period of time (Izquierdo et al., 2001). However, the separation between these two strategies is not clear and there are gradual and mixed strategies between them. A prime example of a species showing such a gradient in strategies is the yellowfin tuna (Thunnus albacares; YFT), which is described as an income-capital breeder (Zudaire et al., 2013b). 
This species affords the cost of reproduction by both strategies, by feeding during the spawning period and using energetic resources it has previously acquired. Despite the fundamental impact that an understanding how size variation in YFT females affects their fecundity and reproductive potential (including the quality of eggs) could have on stock resilience and, hence, management approaches, very few studies to date have been conducted to understand how the size of YFT females affects their reproductive potential (Zudaire et al., 2014). This is mainly due to the operational difficulties (e.g. sampling) and costs in investigating these complex effects in the wild.

Here, we aim to investigate whether the fatty acids profiles in the gonads of Atlantic YFT females are correlated with their size, which in turn could contribute to variation in spawning and recruitment. This study has also important implications in evaluating the potential age/size related females' larger productivity in the Atlantic Ocean, where YFT is still considered for management purposes as a single panmictic population (Pecoraro et al. 2017).

\section{Materials and Methods}

Fish sampling

Females of yellowfin tuna were caught by purse-seine vessels in the Gulf of Guinea (Eastern Atlantic Ocean) from April 2013 to January 2014 (Fig.1). Morphometric measurements, reproductive stage assessment and tissue sampling were carried out at the cannery "Pêche et Froid" of Abidjan, Ivory Coast. For each fish, the fork length $\left(\mathrm{F}_{\mathrm{L}} ; \mathrm{cm}\right)$, the total fish weight $(\mathrm{W} ; \mathrm{kg})$ and gonad weight $\left(\mathrm{W}_{\mathrm{G}} ; \mathrm{g}\right)$ were recorded. Each fish was assigned to a macroscopic maturity stage following the maturity reference scale for this species (Diaha et al. 2015). For the purpose of the present study, we selected 50 spawning capable phase individuals (i.e., with late-maturing or ripe ovaries - for details see Zudaire et al., 2013a) in the $F_{L}$ range of $125.8-154.5 \mathrm{~cm}$ (Fig. 2).

From each female, a cross section of the ovary of 4-5 cm was sampled between the middle and end part of the right or left lobe and preserved in $4 \%$ buffered formaldehyde for further analyses. In addition, a $2 \mathrm{~g}$ sample of gonads was collected and stored frozen in labelled microtubes for fatty acid analysis.

\section{Reproductive analysis}

Histological analysis
Commentato [cp1]: The section on histological analysis is lacking details on the methods used (i.e. embedding material, section thickness, number of sections per individual sample, stain used, etc.). 
Each ovary, being characterized by an asynchronous ovarian development, was classified according to the most advanced oocyte stage present in the ovary (Murua and Motos, 2006), applying the terminology proposed by Brown-Peterson et al., (2011), and established for YFT in Zudaire et al., (2013a): (i) immature phase (primary growth stage [PG]); (ii) developing phase (cortical alveolar [CA], primary vitellogenesis [Vtg1], and secondary vitellogenesis [Vtg2] stages); (iii) spawning-capable phase (tertiary vitellogenesis [Vtg3], germinal vesicle migration [GVM], and hydration stages [HYD]), and (iv) regenerating phase. For the purposes of this work, the 50 females were selected in spawning-capable phase, containing oocytes in the stages Vtg3, GVM and HYD, i.e. the most advanced oocyte development stages. Atresia was not assessed because the brine conservation process used in the purse seines damages the follicle and chorion of the oocytes, making it difficult to accurately quantify alpha-atresia (Zudaire et al., 2013a).

\section{Oocyte size-frequency distribution}

A portion of the preserved ovary of $0.04 \mathrm{~g}( \pm 0.01 \mathrm{~g})$ was collected and analysed for oocyte sizefrequency distribution. Tissue was placed into a filter with a mesh size of $125 \mu \mathrm{m}$ and sprayed with high pressure water to separate the oocytes from the connective tissue. The separated oocytes were located on a gridded plate, photographed at the stereomicroscope with a digital camera and analysed with the ImageJ free software (Rasband, W.S., ImageJ, U.S. National Institutes of Health, Bethesda, Maryland, USA, http://rbs.info.nih.gov/ij/,1997-2012) to count and automatically measure the diameter of all the oocytes. The number of developing oocytes (NDO) was calculated for the oocytes in the developing phase described by a diameter size larger than the minimum threshold diameter of CA oocytes estimated at $120 \mu \mathrm{m}$ (Zudaire et al., 2013b).

\section{Batch fecundity analysis}

The gravimetric method (Hunter et al., 1989) was used to assess the batch fecundity (BF), which is the number of oocytes spawned per batch during the actively spawning phase without presence of new post-ovulatory follicles. This method consists of counting the total number of oocytes in the most advanced maturation stage, i.e. GVM or hydrated oocytes. For this purpose, three tissue subsamples of $0.1 \mathrm{~g}( \pm 0.01)$ were collected from each individual fixed ovary. Each subsample was placed on a slide and covered with 3-4 drops of glycerin to make translucent the oocytes in the GVM and hydrated oocytes (Schaefer, 1987). After oocyte counting, BF was estimated as the weighted mean density of the three subsamples multiplied by the total weight of the ovary. In case that the coefficient of
Commentato [cp2]: The authors describe a method for conducting oocyte size-distribution that is not referenced and without apparent validation. For example, have the authors confirmed that spraying oocytes with high pressure water (without indication as whether it is freshwater or marine water) does not damage nor cause osmotic shock to the oocytes and, therefore, possibly affecting diameter measurements? Please provide a published reference and/or proper validation for this method

Commentato [cp3]: In the description of th gravimetric method used to estimate batch fecundity, please clarify whether (1) the ovarian subsamples were sectioned prior to the use of glycerin, (2) the glycerin-treated samples or sections were stained for contrast, and (3) only GVM and hydrated oocytes were counted. 
variation among the three measurements was higher than $10 \%$, more subsamples were taken until reaching coefficient of variation threshold to decrease the uncertainty around the BF estimate To estimate the relative batch fecundity (BFrel), the value of BF was divided by the gonad-free weight of the fish.

\section{Analysis of fatty acids}

Fatty acids analysis was performed following the same methodology as used in Bodin et al. (2014) and Sardenne et al. (2016). First, ovarian samples were subjected to cryogenic grinding by using a mixer mill MM400 Retsch ${ }^{\circledR}$ (Verder, France), obtaining a homogenized powder. From this, a subsample $(0.1 \pm 0.01 \mathrm{~g})$ was weighed under a nitrogen atmosphere and extracted following the method of Folch et al., (1957). An aliquot of the extracted sample was separated by adsorption chromatography on a silica gel micro-column (Kieselgel 70 to 230 mesh, heated at $450^{\circ} \mathrm{C}$ and deactivated with $6 \%$ water). Neutral and Polar lipids were eluted with $10 \mathrm{~mL}$ chloroform-methanol mixture $(98: 2 \mathrm{v} / \mathrm{v})$ and $20 \mathrm{~mL}$ of methanol, respectively. After adding a known amount of C23:0 fatty acid as internal standard, each fraction was transmethylated at $100^{\circ} \mathrm{C}$ with $10 \mathrm{wt} \%$ boron trifluoride-methanol (Metcalfe and Schmitz, 1961). The fatty acid methyl esters were analysed on a TRACE 1310 gas chromatograph equipped with an on-column injector and a flame-ionization detector (GC-FID, Thermo Scientific). Compounds were separated on a FAMEWAX ${ }^{\mathrm{TM}}$ column ( $30 \mathrm{~m}, 0.32 \mathrm{~mm}$ internal diameter, Restek) using helium as carrier gas at a constant flow of $15 \mathrm{~mL} / \mathrm{min}$. The injector temperature was set at $225^{\circ} \mathrm{C}$ and the oven temperature was raised from $130^{\circ} \mathrm{C}$ to $245^{\circ} \mathrm{C}$ at $2^{\circ} \mathrm{C} / \mathrm{min}$ after a stationary phase at $130^{\circ} \mathrm{C}$ for $1 \mathrm{~min}$. Peaks were identified by comparing sample retention times to those of commercial standard mixtures (Menhaden oil and Food Industry FAME Mix, Restek) with Xcalibur 2.2 software. Results were expressed in $\%$ as the relative abundance of total identified compounds in each lipid fraction. According to their degree of unsaturation (number of ethylenic or "double" bonds), fatty acids were grouped and estimated in saturated fatty acids (SFAs), mono-unsaturated fatty acids (MUFAs) and PUFAs.

\section{Multiple regression analysis}

A multivariate linear regression model was built for the 50 selected spawning capable YFT females in order to understand out how their fatty acid profiles change according to their size.
Commentato [cp4]: Please provide the exact percentages of SFAs, MUFAs and PUFAs for NR and PL (shown in Fig. 3) in the text of the Results section as some of these values are missing. 
A known problem with multiple regression model is the multi-collinearity effects that occur when the predictor variables are too strongly correlated to each other, making the parameter estimates unstable and difficult to interpret. The possible presence of multi-collinearity among explanatory variables was investigated through variance inflation factors (VIF) calculations. All models were implemented with the R statistical platform (R Core Team 2019) and VIF was calculated using the R package car (Fox and Weisberg 2019). For this reason, we built different models for each group of fatty acids (SFAs, MUFAs and PUFAs) and the polar and neutral fractions were tested separately. Finally, the fatty acids from the two lipid fractions with a significant effect on the response variable were aggregated together in the model using the Akaike Information Criterion (AIC) as an objective statistical criterion in order to select the best model, i.e. the one that explains the most variability (deviance) in the data. The stepwise function StepAIC in the R package MASS was used to show the decrease in AIC when additional covariates were added. This allows for a trade-off between the number of covariates and the deviance explained.

\section{Results}

\section{Reproductive analysis}

The mean and median of batch fecundity were estimated at $2.66 \pm 0.9$ and $2.66 \pm 1.2$ million oocytes and of relative batch fecundity at $50.2 \pm 17.6$ and $48.5 \pm 17.4$ oocytes/g of gonad-free weight, respectively (Supplementary Material1). None of these variables were significantly associated with fish size. The mean gonad weight $\left(\mathrm{W}_{\mathrm{G}}\right)$ was +/-1275.9 $\mathrm{g}$, ranging from $655.5 \mathrm{~g}$ to $2305.3 \mathrm{~g}$ (Supplementary Material1). The fish size had a significant effect $(P<0.01)$ on the total number of developing oocytes and $W_{G}$, explaining $12 \%$ and $14.5 \%$ of the variance, respectively. Both variables showed an increase in relation with the fish size.

\section{Analysis of fatty acids}

For NL, SFAs were the most abundant group (44.5\%), while in PL the most abundant groups were SFAs and PUFAs (40.19\% and $40.32 \%$, respectively). Overall, NL contained a higher percentage of SFAs (45.1\%) and MUFAs (21.4 \%) but a lower percentage of PUFAs (33.6\%) than PL (respectively, 43\%, $13.6 \%$ and43.4\%) (Fig.3). The fatty acid C16:0 (palmitic acid) was the most abundant SFA in both fractions (28.8\% in NL vs $29.59 \%$ in PL), followed by C18:0 (stearic acid; $9.54 \%$ NL vs $9.27 \%$ PL). Regarding MUFAs, in each lipid fractions the most abundant fatty acid found was the C18:1n-9 with a 
higher concentration in NL (ranged from 5.16 to $24.10 \%$ ) than in PL (ranged from 7.72 to $17.58 \%$ ). The primary source of total PUFAs found in ovarian tissues were $\omega-3$ fatty acids C20:5n-3 (eicosapentaenoic acid; EPA) and DHA. In NL, it was observed a much higher level of DHA (21.28\%) than eicosapentaenoic acid (EPA; 4.17\%). The arachidonic acid (AA; C20:4n-6) was the most abundant $\omega-6$ PUFA in our samples.

\section{Multiple regression analysis}

The measures of all the reproductive outputs were related to the gonad weight. For this reason, the gonad weight was chosen as the response variable for the multiple linear regression model. In this model, the fork length $\left(F_{L}\right)$ and the fatty acid profiles were used as explanatory variables:

$G \sim F_{L}+F A 1+F A 2+\varepsilon$

where $G$ is the gonad weight, $F_{L}$ is the fish fork length, FA1 and FA2 are the fatty acids profiles, and their ratios, from the neutral $(\mathrm{NL})$ and polar $(\mathrm{PL})$ fractions, respectively $\varepsilon$ are the residuals.

\section{Polar lipids}

For polar lipids, no significant correlation was found among both SFAs and MUFAs groups, $\mathrm{W}_{\mathrm{G}}$ and fish size. Instead, significant correlations were found with some combinations of PUFAs as well as with some $\omega 3$ : $\omega 6$ ratios. For the $\mathrm{PL}$ fraction, a significant correlation $(\mathrm{P}<0.001)$ was detected considering as explanatory variables the sums of $\omega 3$ - and $\omega 6$-PUFAs), with an adjusted coefficient of determination $r^{2}$ of 0.415 (Supplementary Material2). The regression coefficient was positive (Estimate: 3.92) for $\omega 3$ PUFAs, while it was negative for w6-PUFAs (Estimate: -2.52; Supplementary Material2).

Exploring the effects of each PUFA of the polar fraction, we detected that among all the $\omega 3$ and $\omega 6$ fatty acids, only DHA (RC: 51.864), AA (RC: -389.214) and C18:2n-6 (RC: 798.591) had a significant effect on the model, explaining together with the $F_{L}$ around $50 \%$ of the variability in $W_{G}$ (adjusted $r^{2}=$ $0.505, \mathrm{P}<0.001)$. The adjusted $\mathrm{r}^{2}$ further increased to $0.581(\mathrm{P}<0.001)$ by adding the specific interaction of those fatty acids with the fish size to the model (Supplementary Material2).

Neutral lipids 
In neutral lipids, our results showed that some specific SFAs, MUFAs and PUFAs significantly affected the $W_{G}$ variability.

Specifically, for SFAs, C17:0 and C16:0 explained together around $33 \%$ of the variation of the $\mathrm{W}_{\mathrm{G}}$ in relation to fish size (Supplementary Material3). Significant correlations $(\mathrm{P}<0.001)$ were also found with C18:1n-9 and C18:1n-7 (MUFAs), which explained $26 \%$ of the variance in the $W_{G}$ (Table S3). The only two PUFAs, in the neutral fraction, with a significant and positive effect on the model were C20:4n-3 and C18:3n-6 (adjusted $r^{2}=0.37, P<0.001$; Supplementary Material3). For all the considered models, VIF values were always lower than 10 , thus suggesting the absence of severe multi-collinearity.

\section{Multiple regression model for the PUFAS of both fractions}

These two PUFAs C20:4n-3 and C18:3n-6 of the neutral fraction were added in the model, together with the three significant PUFAs detected for the polar fraction (DHA, AA and C18:2n-3). However, the effect of $\mathrm{C} 18: 2 \mathrm{n}-6$ was not significant $(\mathrm{P}>0.05)$ and hence it was removed from the model. Running the model with the other four fatty acids explained almost $57 \%$ (adjusted $r^{2}=0.569$ ) of the variability of the gonad weight and all the explanatory variables considered had a significant effect on the model $(P<0.05 ;$ Table 1). The addition of the interactions between PUFAs and fish size further increased the percentage of variability explained (adjusted $r^{2}=0.668$; Fig. 4). Specifically, the interactions between the fish size with DHA, C20:4n-3 and C18:3n-6 had a positive effect on the model. While AA was the only PUFA with a negative effect on the model. Overall, the interactions of the fish size with the PUFAS have a significant effect on the model $(P<0.05)$

\section{Discussion and conclusions}

Using fish gonad weight, which is a good indicator of the individual reproductive effort, we show that larger YFT females possess larger gonads, probably due to a greater abdominal cavity which enabling the development of larger ovaries for holding eggs. Perhaps more importantly, we also demonstrated for the first time that larger females have different fatty acid profiles in the gonads compared to smaller individuals. Indeed, the dependence on body length of fatty acid profiles in the gonads represents one of the most original results of our study. This is important as the variation in fatty acid profiles across female size classes could result in variation in spawning quality, with larger females potentially producing higher-quality offspring that can in turn improve chance of survival in larvae through a decrease of development duration from embryogenesis to the first oral feeding (FernándezPalacios et al., 2011). Previous studies have already highlighted that size and age can affect YFT 
reproductive potential, with larger females exhibiting a higher spawning fraction in the Eastern Pacific Ocean (Schaefer, 1998) and a longer spawning period in the western Indian Ocean (Zudaire et al., 2013b). Interestingly, the relative batch fecundity of the YFT female in the Eastern Pacific Ocean (Schaefer, 1998) was higher (67.3; range 4.9-174.0) than the one measured in this study in the Atlantic Ocean (50.2; range 14.9-88.9).

The variation in the fatty acid profiles in the gonads of female YFT is particularly evident in certain polyunsaturated fatty acids (PUFAs) especially in polar lipids (PLs). In these latter, the significant correlation of dietary PUFAs with the gonad weight and the fish size emphasizes their functional importance for YFT reproductive processes (Tocher, 2003). Our results also indicate that bigger females with bigger gonads have a higher concentration of specific $\omega 3$ and lower concentration of specific $\omega 6$ PUFAs in the polar fraction.

Tunas cannot synthesize de novo $\omega 3$ and $\omega 6$ PUFAs since they lack of the appropriate fatty acid desaturase enzymes (Tocher, 2003). Thus, the proportion of the different PUFAs in the ovaries reflects the amount consumed by feeding. Balance in the diet of both PUFAs $\omega 3$ and $\omega 6$ is an essential point for optimizing fish reproductive success (Acharia et al., 2000). PUFAs in general, and $\omega 3$ in particular, actively participate in gonad maturation, egg quality (Izquierdo et al., 2001) and larval growth of fish (Tulli and Tibaldi, 1997), regulating also the production of eicosanoids (prostaglandins), steroid hormones and gonad development (ovulation; Izquierdo et al., 2001). Our results indicate that larger females have a higher concentration of docosahexaenoic acid (DHA, C22:6n-3) but a lower concentration of arachidonic acid (AA, C20:4n-6), and linoleic acid (C18:2n-6). DHA is an essential fatty acid that cannot be synthesized by fishes from the essential precursor alpha-linolenic acid (Riediger et al., 2009). It has a specific structural role in nervous tissue (Sargent et al., 1993) and high supply of DHA available after the start of feeding supports the rapid development of membrane systems (Tocher, 2003). In other fish species, it was observed a positive correlation between the responsiveness to a visual stimulus and a higher concentration of DHA in the neural tissue in the head, in relation with the larvae's size (Burns and Fuiman 2019). Our results confirm that usually tuna lipids, including triacyglycerols and phospholipids, have higher levels of DHA than EPA in the neutral fraction (Murase and Saito, 1996).

Overall, we detected a higher PUFAs $\omega 3 / \omega 6$ ratio in PLs than in NLs of larger YFT females. These results show that an increase of gonad weight in larger females corresponds also to a decrease of arachidonic acid (AA) and a consequent increase of EPA/AA ratio. Higher levels of EPA/AA ratio, which is crucial for determining eicosanoid actions, have been associated with a superior resistance to infection in several marine and freshwater species (Sargent et al., 1995). Therefore, dietary intake of these fatty acids can assume a relevant importance in YFT reproduction, even if there is no information about the 
optimal intake of $\omega 3$ to guarantee the highest spawning quality and reproductive success of this species.

High levels of $\omega 3$ in lipids and, in particular of DHA and EPA are a prerogative of tuna species (Murase and Saito, 1996). For instance, the Pacific YFT showed a total amount of $\omega 3$ PUFAs around $35 \%$ of total fatty acids with DHA alone accounting for 25\%-30\% (Sunarya et al., 1995). Although the relatively high level of $\omega 3$ for YFT females seems to be an intrinsic characteristic of tuna species, the higher amount of $\omega 3$ in the gonads of larger females measured in this study may indicate a quantitative change in the energetic strategy of retaining/accumulating those fatty acids for reproduction (Tocher, 2003).

In the neutral fraction, we observed a higher level of palmitic acid (C16:0) for SFAs and oleic acid (C18:1n-9) for MUFAs significantly correlated with the gonad weight and the size of the females. These fatty acids have important quantitative and qualitative roles in structural phospholipids (Bell and Dick, 1991) and they can be biosynthesized de novo by fish as well as by all known organisms (Sargent et al., 1989).

YFT individuals rely on the schooling behaviour of their prey to facilitate feeding, forming groups of individuals with different size and age. Most of the large volume tuna fisheries rely on their target species' tendency to aggregate in schools. For this reason, when the females were caught, most likely they were catching the same prey. Therefore, the differences in proportions of fatty acid profiles between individuals highlighted in this study was not a result of the different maternally-derived nutrients, as instead already indicated in other studies (Burns and Fuiman 2019). Clearly, the ontogenetic shift in the relative proportion of different fatty acids identified in this study is distinct from previous results focusing on overall investment of energy resources in this species. Indeed, a previous study has shown that smaller YFT females invest more energetic resources for somatic growth than larger ones (Zudaire et al. 2014). In this study, the authors showed a negative relationship between the amount of total lipids in the muscle and the size of YFT females. Therefore, larger mothers may switch the energy allocation from somatic to gonad growth for ensuring future reproductive opportunities (Wiegand et al., 2007). This size-related energy allocation strategy might be linked to a much higher natural mortality rate in females with a $F_{L}>130 \mathrm{~cm}$ than in midsize individuals (Hampton and Fournier, 2001).

Future effort is needed to determine the fatty acid composition in somatic tissues such as white muscle and liver in order to understand how energy is transferred from those tissues to the gonads during spawning seasons and events in relation to female size. This information is crucial to confirm the size-related fatty acids composition pattern observed in the gonads of YFT females by the dynamics of the somatic energy reserves during reproduction. According to the evidence of YFT 
population structure detected among oceans (Pecoraro et al. 2016, 2017), further studies have to investigate how the fatty acid profiles in the gonads of female YFT varies in relation to their size in each ocean.

The use of the spawning stock biomass as a proxy of YFT stock reproductive potential by the tRFMOs is still a subject of debate (Zudaire et al., 2014). The reproductive contribution of large females should be further investigated in order to assist the management framework of YFT in the Atlantic Ocean. Additional demographic criteria accounting for the reproductive importance of larger and most experienced spawners, will also contribute to a proper estimation of the reproductive potential of YFT stocks.

In such a context, a shared effort among the different Regional fisheries management organisations (RFMOS) would be key to optimize the sampling of large individuals, which is one of the most challenging tasks for these pelagic fish species. Protecting those larger spawners may increase per capita reproductive output (Kaiser et al., 2007) and, hence, contribute to increase prospects of better offspring survival. Conversely, increasing the mortality of larger and most experienced spawners might relatively reduce in larger proportions the reproductive potential of the stock, which could also alter the time and the location of spawning events decreasing the production and quality of eggs released. As large YFT females could have a crucial relative reproductive value (Grey and Law, 1987), intensely contributing to year class strength and surplus production under exploited conditions (Arlinghaus et al., 2010), their protection could be a potential management measure to ensure the sustainability of YFT in the Atlantic Ocean.

\section{References}

Acharia, K., Lal, B., Singh, T.P., and Pati, A.K. 2000. Circadian Phase Dependent Thermal Stimulation of Ovarian Recrudescence in Indian Catfish, (Clarias batrachus), Biological Rhythm Research, 31: 125-135.

Alonso-Fernández, A., and Sabórido-Rey, F. 2012. Relationship between energy allocation and reproductive strategy in Trisopterus luscus. The Journal of Experimental Marine Biology and Ecology, 416: 8-16. 
Aristizabal, E.O. 2007. Energy investment in the annual reproduction cycle of female red porgy, (Pagrus pagrus)(L.). Marine Biology, 152: 713-724.

Arlinghaus, R., Matsumura, S., and Dieckmann, U. 2010. The conservation and fishery benefits of protecting large pike (Esox Lucius)(L.) by harvest regulations in recreational fishing. Biological Conservation, 143: 1444-1459.

Bell, M.V., and Dick, J.R. 1991. Molecular species composition of the major diacyl glycerophospholipids from muscle, liver, retina and brain of cod (Gadus morhua). Lipids, 26: 565-573.

Berkeley, S.A., Chapman C., and Sogard, S.M. 2004. Maternal age as a determinant of larval growth and survival in a marine fish, Sebastes melanops. Ecology, 85: 1258-1264.

Birkeland, C., and Dayton P.K. 2005. The importance in fishery management of leaving the big ones. Trends in Ecology \& Evolution, 20: 356-358.

Bobko, S.J., and Berkeley, S.A. 2004. Maturity, ovarian cycle, fecundity, and age-specific parturition of black rockfish (Sebastes melanops). Fishery Bulletin, 102: 418-429.

Bodin, N., Lucas, V., Dewals, P., Adeline, M., Esparon, J., Chassot, E. 2014. Effect of brine immersion freezing on the determination of ecological tracers in fish. European Food Research and Technology, 238: 1057-1062.

Brown-Peterson, N.J., Wyanski, D.M., Saborido-Rey, F., Macewicz, B.J., and Lowerre-Barbieri, S.K. 2011. A standardized terminology for describing reproductive development in fishes. Marine and Coastal Fisheries, 3: 52-70.

Burns, C.M., and Fuiman L. A. 2019. Maternally derived nutrients influence fatty acid composition and predator evasion behaviour of larval southern flounder, Paralichthys lethostigma. Journal of Experimental Marine Biology and Ecology, 514-515: 41-47.

Cardinale, M., and Arrhenius, F. 2000. The relationship between stock and recruitment: are the assumptions valid? The Marine Ecology Progress Series, 196: 305-309.

Diaha, N.C., Zudaire, I., Chassot, E., Pecoraro, C., Bodin, N., Amandè, M.J., Dewals, P., Romeo M.U., Irié, Y.D., Barryga, B.D., Gbeazere, D.A., Kouadio, D. 2015. Present and future of reproductive biology studies of yellowfin tuna (Thunnus albacares) in the eastern Atlantic Ocean. Collective Volume of Scientific Papers - ICCAT, 71 (1), 489-509. ISSN 1021-5212.

Fernández-Palacios, H., Norberg, B., Izquierdo, M., and Hamre, K. 2011. Effects of Broodstock Diet on Eggs and Larvae. In Larval Fish Nutrition, G. J. Holt (Ed).

Folch, J., Lees, M., and Sloane-Stanley, G.H. 1957. A simple method for the isolation and purification of total lipids from animal tissues. The Journal of Biological Chemistry, 226: 497-509.

Fox, J., and Weisberg, S. 2019. An R Companion to Applied Regression, Third edition. Sage, Thousand Oaks CA.

Grey, D.R., and Law, R. 1987. Reproductive values and maximum yields. Functional Ecology, Volume 1, No. 4, pp. 327-330: 327-330.

Hampton, J., and Fournier, D.A. 2001. A spatially disaggregated, length-based, age-structured population model of yellowfin tuna (Thunnus albacares) in the western and central Pacific Ocean. Marine Freshwater Research, 52: 937-963. 
Hunter, J.R., Macewicz, B.J., and Kimbrell, C.A. 1989. Fecundity and other aspects of the reproduction of sablefish, Anoplopoma fimbria, in central California waters. California cooperative oceanic fisheries investigations Reports, 30: 61-72.

Izquierdo, M.S., Fernandez-Palacios, H., and Tacon A.G.J. 2001. Effect of broodstock nutrition on reproductive performance of fish. Aquaculture, 197: 25-42.

Kaiser, M.J., Blyth-Skyrme, R.E., Hart, P.J., Edwards-Jones, G., and Palmer, D. 2007. Evidence for greater reproductive output per unit area in areas protected from fishing. Canadian Journal of Fisheries and Aquatic Sciences, 64: 1284-1289.

Kell, L.T., Nash, R.D.M., Dickey-Collas, M., Mosqueira, I., and Szuwalski, C. 2015. Is spawning stock biomass a robust proxy for reproductive potential? Fish Fisheries, 17: 596-616.

Kjesbu, O.S., Witthames, P.R., Solemdal, P., and Walker, M.G. 1998. Temporal variations in the fecundity of Arcto-Norwegian cod (Gadus morhua) in response to natural changes in food and temperature. Journal of Sea Research, 40: 303-321.

Lowerre-Barbieri, S.K., Ganias, K., Saborido-Rey, F., Murua, H., and Hunter, J.R. 2011. Reproductive timing in marine fishes: variability, temporal scales, and methods. Marine and Coastal Fisheries, 3: 71-91.

Marshall, C.T., Kjesbu, O.S., Yaragina, N.A., Solemdal, P., and Ulltang, $\varnothing$. 1998. Is spawner biomass a sensitive measure of the reproductive and recruitment potential of Northeast Arctic cod? Canadian Journal of Fisheries and Aquatic Sciences, 55: 1766-1783.

Marshall, C.T., Yaragina, N.A., Lambert, Y., and Kjesbu, O.S. 1999. Total lipid energy as a proxy for total egg production by fish stocks. Nature, 402: 288-290.

Metcalfe, L.D., and Schmitz, A.A. 1961. The rapid preparation of fatty acid esters for gas chromatographic analysis. Analytical Chemistry, 33: 363-364.

Myers, R.A., and Mertz, G. 1998. Reducing uncertainty in the biological basis of fisheries management by meta-analysis of data from many populations: a synthesis. Fisheries Research, 37: 51-60.

Morgan, M.J., Murua, H., Kraus, G., Lambert, Y., Marteinsdottir, G., Marshall, C.T., O'Brien, L., and Tomkiewicz, J. 2009. The evaluation of reference points and stock productivity in the context of alternative indices of stock reproductive potential. Canadian Journal of Fisheries and Aquatic Sciences, 66: 404-414.

Murase, T., and Saito, H. 1996. The docosahexaenoic acid content in the lipid of albacore (Thunnus alalunga) caught in two separate localities. Fisheries Science, 62: 634-638.

Murawski, S.A., Rago, P.J., Trippel, E.A. 2001. Impacts of demographic variation in spawning characteristics on reference points for fishery management. ICES Journal of Marine Science, 58: 1002-1014.

Murua, H., Kraus, G., Saborido-Rey, F., Witthames, P.R., Thorsen, A., Junquera, S. 2003a. Procedures to estimate fecundity of marine fish species in relation to their reproductive strategy. Journal of Northwest Atlantic Fishery Science, 33: 33-54.

Murua, H., Saborido-Rey, F. 2003b. Female reproductive strategies of commercially important fish species in the North Atlantic. Journal of Northwest Atlantic Fishery Science Vol. 33: 23-32. 
Murua, H., and Motos, L. 2006. Reproductive strategy and spawning activity of the European hake (Merluccius merluccius) (L.) in the Bay of Biscay. Journal of Fish Biology, 69: 1288-1303.

Pecoraro, C., Babbucci, M., Villamor, A., Franch, R., Papetti, C., Leroy, B., Ortega-Garcia, S., Muir, J., Rooker, J., Arocha, F., Murua, H., Zudaire, I., Chassot, E., Bodin, N., Tinti, F., Bargelloni, L., Cariani, A. 2016. Methodologic assessment of 2b-Rad genotyping technique for population structure inferences in yellowfin tuna (Thunnus albacares). Marine Genomics 25: 43-48.

Pecoraro, C., Zudaire, I., Bodin, N., Murua, H., Taconet, P., Diaz-Jaimes, P., Cariani, A., Tinti, F., and Chassot, E. 2017. Putting all the pieces together: Integrating current knowledge of biology, ecology, fisheries status, stock structure and management of Yellowfin Tuna (Thunnus albacares). Reviews in Fish Biology and Fisheries, 27: 811-841.

Riediger, N.D., Othman, R.A., Suh, M., Moghadasian, M.H. 2009. A systemic review of the roles of $n-3$ fatty acids in health and disease. Journal of the American Dietetic Association, 109: 668-679.

Riveiro, I., Guisande, C., Maneiro, I., and Vergara, A.R. 2004. Parental effects in the European sardine (Sardina pilchardus). Marine Ecology Progress Series, 274: 225-234.

Sardenne, F., Bodin, N., Chassot, E., Amiel, A., Fouché, E., Degroote, M., Hollanda, S.J., Pethybridge, H., Lebreton, B., Guillou, G., Ménard, 2016. Trophic niches of sympatric tropical tuna in the Western Indian Ocean inferred by stable isotopes and neutral fatty acids. Progress in Oceanography, 146: 75-88.

Sargent, J.R. 1989. Ether-linked glycerides in marine animals. Marine biogenic lipids, fats and oils, In CRC Press, pp. 176-193. Ed. by R., G. Ackman. Boca Raton, Florida.

Sargent, J.R., Bell, J.G., Bell, M.V., Henderson, R.J., and Tocher, D.R. 1993. The metabolism of phospholipids and polyunsaturated fatty acids in fish. Aquaculture: Fundamental and Applied Research, 43: 103-124.

Sargent, J.R., Bell, J.G., Bell, M.V., Henderson, R.J., and Tocher, D.R. 1995. Requirement criteria for essential fatty acids. Journal of applied ichthyology, 11: 183-198.

Sargent, J.R., Tocher, D.R., \& Bell, J.G. 2002. The lipids. In: Fish Nutrition, $3^{\text {rd }}$ edn, pp.181-257. Ed. By Halver, J.E., Hardy, R.W., Elsevier (Academic Press), San Diego, California.

Schaefer, K.M. 1987. Reproductive biology of black skipjack, (Euthynnus lineatus), an eastern Pacific tuna. Inter-American Tropical Tuna Commission Bulletin, 19: 166-260.

Schaefer, K.M. 1998. Reproductive biology of yellowfin tuna (Thunnus albacares) in the eastern Pacific Ocean". Inter-American Tropical Tuna Commission, 21: 201-272.

Scott, B., Marteinsdottir, G., and Wright, P. 1999. Potential effects of maternal factors on spawning stock-recruitment relationships under varying fishing pressure. Canadian Journal of Fisheries and Aquatic Sciences, 56: 1882-1890.

Shelton, A.O., Hutchings, J.A., Waples, R.S., Keith, D.M., Akçakaya, H.R., and Dulvy, N.K. 2015. Maternal age effects on Atlantic cod recruitment and implications for future population trajectories. ICES Journal of Marine Science, 72: 1769-1778.

Sunarya, W., Fitriati M. and Mulyani H. 1995. The effect of season on fat content and fattyacid profile especially $n-3$ of yellowfin tuna. Res. Contrib. IX Session Indo-PacificFishery Commission Working Party on Fish Technology and Marketing. FAO Fish.Rep., 514 Suppl: 205-209. 
Tocher, D.R. 2003. Metabolism and functions of lipids and fatty acids in teleost fish. Reviews in Fisheries Science, 11: 107-184.

Tomkiewicz, J., Tybjerg, L., and Jespersen, AA. 2003. Micro-and macroscopic characteristics to stage gonadal maturation of female Baltic cod. The Journal of Fish Biology, 62: 253-275.

Trippel, E.A., 1999. Estimation of stock reproductive potential: history and challenges for Canadian Atlantic gadoid stock assessments. Journal of Northwest Atlantic Fishery Science, 25: 61-82.

Tulli, F., and Tibaldi, E. 1997. Changes in amino acids and essential fatty acids during early larval rearing of dentex. Aquaculture International, 5: 229-236.

Watanabe, T. 1982. Lipids nutrition in fish. Comparative Biochemistry 73: 3-15.

Wiegand, M.D., Johnston, T.A., Leggett, W.C., Watchorn, K.E., Ballevona, A.J., Porteous, L.R., Casselman, J.M. 2007. Contrasting strategies of ova lipid provisioning in relation to maternal characteristics in three walleyes (Sander vitreus) populations. Canadian Journal of Fisheries and Aquatic Sciences, 64: 700-712.

Zudaire, I., Murua, H., Grande, M., Korta, M., Arrizabalagaet, H., Areso, J.J., and Delgado-Molina, A. 2013a. Fecundity regulation strategy of the yellowfin tuna (Thunnus albacares) in the Western Indian Ocean. Fisheries Research 138: 80-88.

Zudaire, I., Murua, H., Grande, M., and Bodin, N. 2013b. Reproductive potential of yellowfin tuna (Thunnus albacares) in the western Indian Ocean. Fisheries Bulletin, 111: 252-264.

Zudaire, I., Murua, H., Grande, M., Pernet, F., and Bodin, N. 2014. Accumulation and mobilization of lipids in relation to reproduction of yellowfin tuna (Thunnus albacares) in the Western Indian Ocean. Fisheries Research, 160: 50-59. 
Fig. 1_Geographic origin of the yellowfin females sampled for this study. Each dot indicates a purse seine fishing set. Dots are plotted with some transparency to indicate an overlap of fishing seats hidden due to overplotting issue.

Fig. 2_ Distribution by $10-\mathrm{cm}$ length classes for the 50 female yellowfin tuna sampled.

Fig. 3_ Stacked bar chart with the different concentration (in \%) of the three fatty acid groups (SFA,

Fig. 4_Scatter plots for the results of the final multiple regression model. The gonad weight $\left(W_{G}, g\right)$ is the response variable and fork length $\left(F_{L}, \mathrm{~cm}\right)$ and the interaction of the fatty acids (C20:4n-3, C18:3n5436 for the NL in green and C22:6n-3, C20:4n-6 for PL in blue) with the FL are the explanatory variables. All the variables were scaled to perform the multiple regression model. The solid three lines indicate the mean regression line and they were chosen automatically by the $\mathrm{R}$ package ggeffects for each facet individually. The shaded areas represent the $95 \%$ confidence level.

Table 1_Summary of the regression coefficients of each variable included in the model. The total 


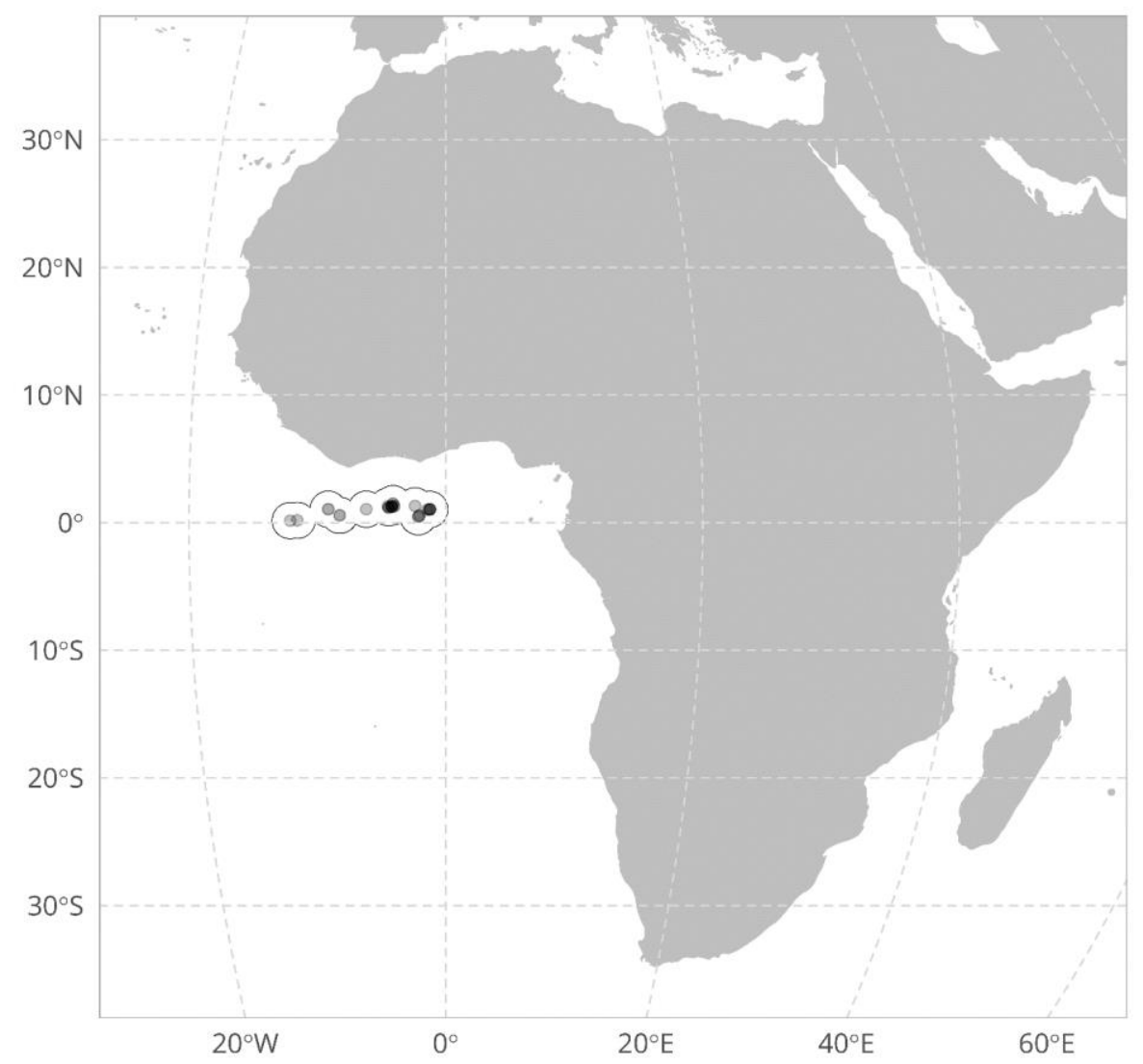

555

556

557

558 


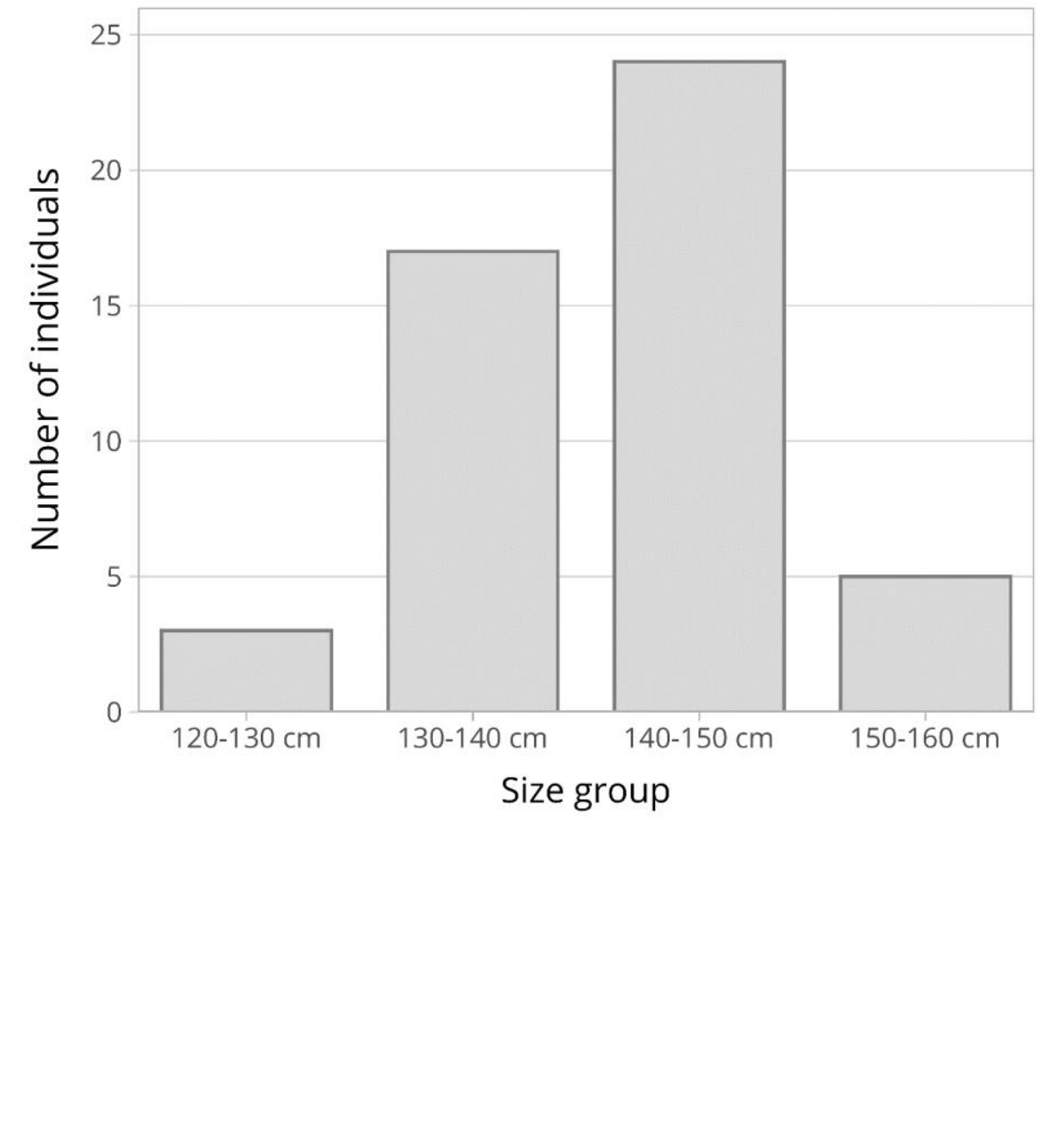




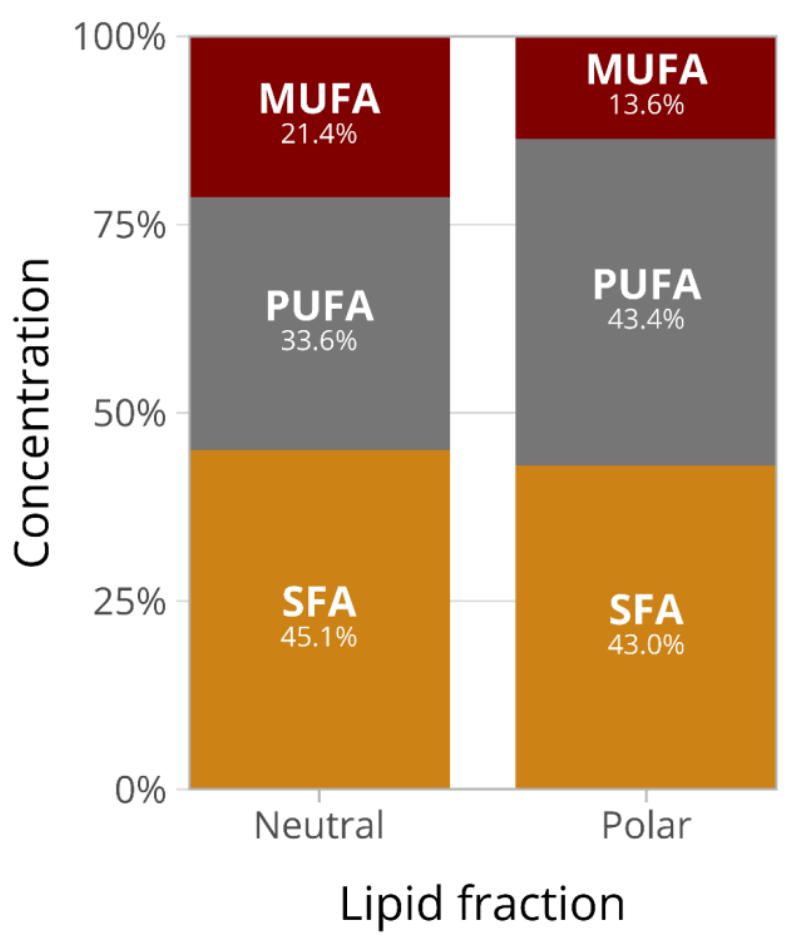

568 


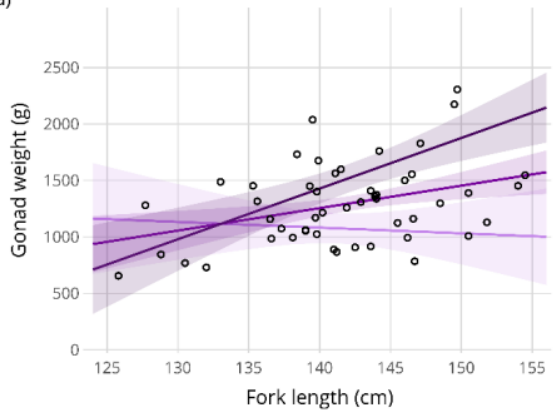

C22:6n-3 polar lipid fraction

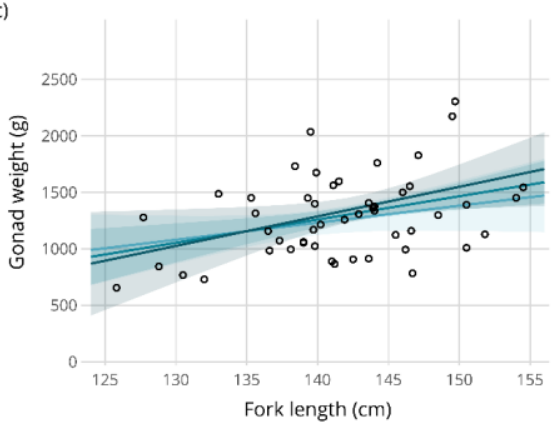

C18:3n-6 neutral lipid fraction

572

573

574

575

\section{3}

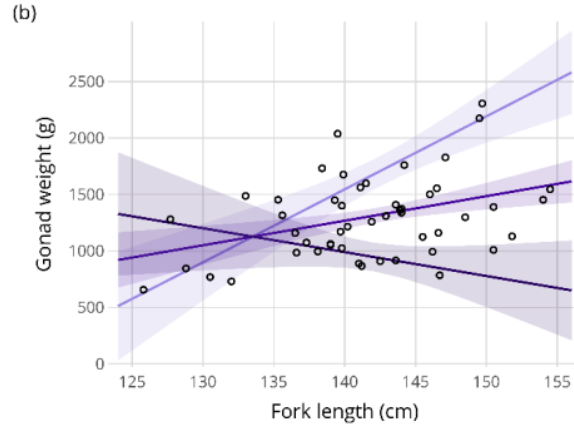

C20:4n-6 polar lipid fraction

(d)

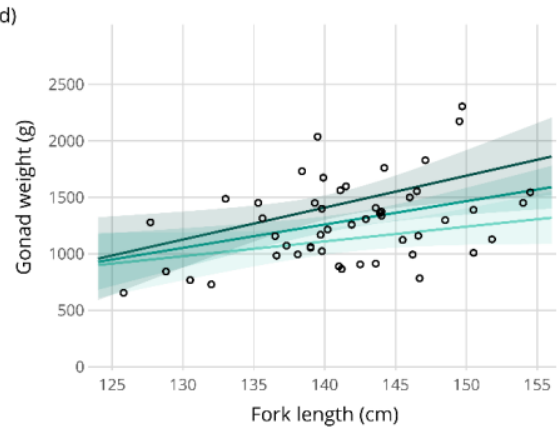

C20:4n-3 neutral lipid fraction $-0.15 \square 0 \square 0.15$ 


\begin{tabular}{|l|l|l|l|l|l|}
\hline & Estimate & Std. Error & t value & p value & vif \\
\hline (Intercept) & 5.539 & 33.971 & 0.163 & 0.871271 & \\
\hline $\mathbf{F}$ & 20.779 & 5.618 & 3.699 & 0.000636 & 1.11 \\
\hline C22:6n-3 PL & 32.088 & 10.971 & 2.925 & 0.005591 & 4.22 \\
\hline C20:4n-6 PL & -321.181 & 65.992 & -4.867 & $1.72 \mathrm{E}-05$ & 3.49 \\
\hline C20:4n-3 NL & 1016.626 & 336.109 & 3.025 & 0.004283 & 2.15 \\
\hline C18:3n-6 NL & 479.57 & 243.453 & 1.97 & 0.055634 & 1.24 \\
\hline Adjusted r & 0.5972 & & & & \\
\hline p value & $5.21 \mathrm{E}-08$ & & & & \\
\hline
\end{tabular}

